\title{
ANTIBACTERIAL ACTIVITY OF EXTRACTS OF ACACIA AROMA AGAINST METHICILLIN-RESISTANT AND METHICILLIN-SENSITIVE STAPHYLOCOCCUS
}

\author{
Mattana, C.M. ${ }^{1 *}$; Satorres, S.E. ${ }^{1}$; Sosa, A. ${ }^{2}$; Fusco, M. ${ }^{2}$; Alcaráz L.E. ${ }^{1}$ \\ ${ }^{1}$ Area Microbiologia, Facultad de Química, Bioquímica y Farmacia. Universidad Nacional de San Luis, Chacabuco y Pedernera, \\ 5700 San Luis, Argentina; ${ }^{2}$ Area de Farmacognosia. Facultad de Química, Bioquímica y Farmacia. Universidad Nacional de San \\ Luis, Chacabuco y Pedernera, 5700 San Luis, Argentina.
}

Submitted: June 23, 2009; Returned to authors for corrections: September 04, 2009; Approved: February 18, 2010.

\begin{abstract}
Antibacterial activity of organic and aqueous extracts of Acacia aroma was evaluated against methicillinresistant Staphylococcus aureus (MRSA), methicillin sensitive Staphylococcus aureus (MSSA) and methicillin-resistant Staphylococcus epidermidis. Inhibition of bacterial growth was determined using agar diffusion and bioautographic methods. Among all assayed organic extracts only ethanolic and ethyl acetate extracts presented highest activities against all tested Staphylococcus strains with minimal inhibitory concentration (MIC) values ranging from 2.5 to $10 \mathrm{mg} / \mathrm{ml}$ and from 2.5 to $5 \mathrm{mg} / \mathrm{ml}$ respectively. The aqueous extracts show little antibacterial activity against Staphylococcus strains. The bioautography assay demonstrated well-defined growth inhibition zones against $S$. aureus in correspondence with flavonoids and saponins. A. aroma would be an interesting topic for further study and possibly for an alternative treatment for skin infections.
\end{abstract}

Key words: Acacia aroma; Antibacterial activity; Staphylococcus; Tusca.

\section{INTRODUCTION}

The indiscriminate use of commercial antimicrobial drugs commonly employed in the treatment of infectious diseases, and the bacterial genetic ability to transmit and acquire resistance to drugs, which are utilized as therapeutic agents has compromised the use of newer generations of antibiotics (13, 17). This situation is growing and the outlook for the use of antimicrobial drugs in the future is still uncertain. Therefore, actions must be taken to reduce this problem; for example, controlling the use of antibiotics, developing research to better understand the genetic mechanisms of resistance, and continuing studies to develop new drugs, either synthetic or natural.

Plants have been a valuable source of natural products for human health care, and the use of plant compounds for pharmaceutical purposes has gradually increased around the world $(7,8,16,18)$.

Most studies on the antibacterial activity of plant extracts have been restricted to analysis of their bacteriostactic and bactericidal properties $(6,8,18,25)$. New assays investigating other potential roles, such as the mediation of pathogenicity via quorum sensing inhibition, have recently emerged (20).

The use of plants against skin disease is a common 
practice in the popular medicine of most cultures, although the precise cause of disease and mechanism of cure is not always understood. Staphylococcus aureus and Staphylococcus epidermidis are ubiquitous colonizer of the skin and mucous membranes of humans and animals. Many strains of $S$. aureus carry resistance genes for penicillin, tetracyclines, methicillin and now, vancomycin. Methicillin-resistant Staphylococcus aureus (MRSA) is a major pathogen causing nosocomial infections, but it has emerged as a problematic pathogen in the community setting as well. These strains called CommunityAssociated Methicillin-Resistant Staphylococcus aureus (CAMRSA) cause infections in healthy individuals without predisponent risk factor and outside the hospital setting. MRSA and CA-MRSA presents a significant threat to public health and are difficult to manage (14). Vancomycin and other glycopeptides antibiotics are the current mainstay of therapy for infections caused by MRSA. However, therapy with glycopeptides is frequently accompanied by side effects and possible risk of emergence of isolates with reduced susceptibility to vancomycin, such as VancomycinIntermediate Staphylococcus aureus (VISA) and heterogeneous VISA (hVISA) (2); hence, there is a constant need for new and effective therapeutic agents, being the phytomedicine a valid alternative.

Acacia aroma, commonly known as tusca (4), a native species of Argentina, is member of genus Acacia subgenus Acacia, which grow widely in the provinces of Tucumán, Salta, Santiago del Estero, Catamarca, La Rioja, Formosa, Chaco, Córdoba, San Luis and Santa Fe (5). This plant is used in Argentine folkloric medicine for wound healing, antiseptic and for the treatment of gastrointestinal disorders. Leaf and bark infusions have diuretic, anti-inflammatory and cicatrizing uses.

The acceptance of traditional medicine as an alternative form for health care and the development of microbial resistance to the available antibiotics has led authors to determine the antibacterial properties of A. aroma and validate the popular use of this plant.

The purpose of the presents study was to investigate the antibacterial activity of leaf extracts of $A$. aroma against methicillin-resistant $S$. aureus (MRSA), methicillin-sensitive $S$. aureus (MSSA) and methicillin-resistant $S$. epidermidis isolates in infected skin wounds. The extracts with the highest antibacterial effectiveness could be of therapeutic usefulness for subsequent application in pharmaceutical formulations against Staphylococcus spp.

\section{MATERIALS AND METHODS}

\section{Plant material}

Aerial parts of Acacia aroma were collected in DecemberJanuary 2007, in the Northwestern region of the Province of San Luis, Argentina. Acacia aroma (Fabaceae) was authenticated by Dr. Del Vitto, Botany Department, San Luis National University (UNSL). A voucher specimen was deposited in the herbarium of UNSL under the number 487. The parts used were leaves.

\section{Preparation of Acacia aroma extracts}

\section{Aqueous extracts:}

- Infusion: It was prepared according to Farmacopea Argentina 6th ed. 1978 (9), applying constant action of hot water during $20 \mathrm{~min}$.

- Decoction: Dried and powdered plant material (5g) was boiled with $70 \mathrm{ml}$ of water for $20 \mathrm{~min}$. After cooling to $40-45^{\circ} \mathrm{C}$, the liquid was filtered and the volume adjusted to $100 \mathrm{ml}$ with distilled water (9).

Organics extracts: A known amount of powdered plant material (100 g) was sequentially extracted at room temperature with solvents of increasing polarity: petroleum ether $\left(60-80^{\circ} \mathrm{C}\right)$, dichloromethane, diethyl acetate, methanol and ethanol. The extracts were filtered through Whatman $n^{\circ} 4$ filter paper, dried under reduced pressure at $40^{\circ} \mathrm{C}$, and weighed.

\section{Microorganisms and media}

The assayed microorganisms used in this study were as 
followed: I-Local clinical isolates: methicillin resistant Staphylococcus aureus $(\mathrm{n}=20)$, methicillin sensitive $S$. aureus $(\mathrm{n}=18)$, methicillin resistant Staphylococcus epidermidis $(n=16)$ obtained from skin diseases. The written informed consent was obtained from all subjects prior to the study. IIReference strains: Staphylococcus aureus ATCC 29213, Staphylococcus aureus ATCC 43300 and Staphylococcus epidermidis ATCC 12228.

The strains were identified by the use of Biochemical profiles according to the recommendations of the Manual of Clinical Microbiology (15). All organisms were maintained in brain-heart infusion (BHI medium) containing 30\% (v/v) glycerol at $-20^{\circ} \mathrm{C}$. The inocula were prepared by adjusting the turbidity of the suspension to match the $0.5 \mathrm{Mc}$ Farland.

\section{Antibacterial testing}

Antibacterial activity of the crude organic extracts and aqueous extract were determined by the modified agar well diffusion method of Perez et al. (19). The different organic extracts were dissolved in dimethylsulfoxide (DMSO) and the aqueous extracts were dissolved in water. The extracts were sterilized by filtration through a $0.2 \mu$ membrane filter.

\section{Agar diffusion assay}

The agar well diffusion method was employed. MuellerHinton agar (MHA, Laboratorios Britania, Argentina) $25 \mathrm{ml}$ was poured into each petri plate. Once the agar solidified, the microorganisms were inoculated on the surface of the plates (1 $\left.\times 10^{8} \mathrm{CFU} / \mathrm{ml}\right)$. Subsequently, the surface of the agar was punched with a 6-mm-diameter wells. Each well was filled with $50 \mu \mathrm{l}$ of each plant extract. The concentration of the extracts employed was $20 \mathrm{mg} / \mathrm{ml}$. Simultaneously, gentamicin sulfate was used as positive control $(1 \mu \mathrm{g}$ per well). Control wells containing the same volume of DMSO, diethyl acetate, ethanol, petroleum ether, dichloromethane, and distilled water were made. After a 24 -hour incubation at $35^{\circ} \mathrm{C}$, all plates were observed for zones of growth inhibition, and the diameter of these zones was measured in millimeters.

All tests were performed in duplicate and the antibacterial activity was expressed as the mean of inhibition diameters ( $\mathrm{mm})$ produced.

\section{Minimal inhibitory concentration (MIC)}

Serial agar macro-dilution method: The tests were performed in MHA medium. After cooling and drying, the plates were inoculated with swabs containing each bacterial cell suspension $\left(1 \times 10^{8} \mathrm{CFU} / \mathrm{ml}\right)$. Then, the surface of the agar was punched with 6-mm-diameter wells. Serial two-fold dilution of each extract were added in each well in a concentration ranging from $20 \mathrm{mg} / \mathrm{ml}$ to $2.5 \mathrm{mg} / \mathrm{ml}$. The plates were incubated aerobically for 24 hours at $37^{\circ} \mathrm{C}$. A growth control of each tested strain was included.

MIC was defined as the lowest concentration of A. aroma extract in which no colony was observed after incubation

\section{Phytochemical screening}

\section{Characterization of chemical metabolites:}

- Detection of glucides: Regular methods were carried out using developers: Molisch reactive $(\alpha-$ Naftol and $\mathrm{H}_{2} \mathrm{SO}_{4}$ ) for the detection and differentiation of glucides. Positive result was indicated by purple coloring.

- Detection of tannin: $5 \mathrm{ml}$ of plant extract was evaporated and the remains were dissolved in 10 $\mathrm{ml}$ of distilled water. The aqueous extract was divided into three parts: $1-2$ drops of $10 \%$ ferric chloride solution were added to one of the parts, a blue coloring indicated the possible presence of hydrolysable tannin. The remaining parts were poured with gelatin, and lead acetate solution at $10 \%$. The occurrence of white precipitate indicated a positive result for the tannin test.

- Detection of flavonoids: For the visualization of flavonoids UV light was used, previously exposing the specimen to ammonia vapors (ionization in basic medium) giving an intense yellow coloring for positive results.

- Detection of saponins: The reaction was 
- performed in a test tube evaporating $5 \mathrm{ml}$ of the extract, then it was shaken vigorously, and left to settle for a period of 15 to $20 \mathrm{~min}$. The presence of saponins was classified by the height and permanence of the foam formation, being observed for $5 \mathrm{~min}$.

- Detection of alkaloids: $30 \mathrm{ml}$ of the plant extract was dried, and then, adding $5 \mathrm{ml}$ of hydrochloric acid at $10 \%$ to it. After filtering, some drops of alkaloid precipitation reactive were added. A slight turbidity or precipitate colored proves the possible presence of alkaloids.

The determinations were done according to the recommendations of the Manual of Farmacognosis (12).

\section{Thin-Layer chromatography (TLC)}

Ethanolic and ethyl acetate extracts were analyzed for TLC. The volume of injection of both extracts was fixed at $3 \mu 1$ $(20 \mathrm{mg} / \mathrm{ml})$ which were spotted on chromatographic silica gel 60 F254 plates (Merck). To detect flavonoids three different solvent systems were used: ethyl acetate:formic acid:methyl ethyl acetone:water (5:1:3:1); ethyl acetate:formic acid:water:methanol (10:2:2:1); ethanol: chloroform (1:3). Spots were visualized by UV light. For the detection of sapogenines, chloroform:methanol:water (70:30:4); buthanol: acetic acid:water $(4: 1: 1)$ chloroform:methanol:water (65:35:10) were used as development solvents. Revealing with a mix of $5 \%$ of sulfur in ethanol, $1 \%$ of vanillin in ethanol and heat. Three micro liters of rutine, quercetin, oleanolic acid and ß-amirin were used as standards. TLC plates were dried overnight in a sterile room for complete removal of solvent.

\section{Bioautography}

Developed TLC plates were covered with 1-2 mm layer of soft medium (BHI agar $0.6 \%$ ) containing $0.1 \%$ (w/v) 2,3,5 triphenyltetrazolium chloride (tetrazolium red) and a suspension of $S$. aureus at a final concentration of $10^{7}$ $\mathrm{CFU} / \mathrm{ml}$. The plates were placed in a sterile tray, sealed to prevent the thin agar layer from drying, and incubated at $37^{\circ} \mathrm{C}$ for $24 \mathrm{~h}$. Where bacterial growth has been inhibited, an uncolored area can be seen on the deep pink-red background. The plates were run in duplicate.

\section{RESULTS AND DISCUSSION}

The antibacterial activity of leaves of Acacia aroma was assayed in vitro conditions by agar well diffusion method against Staphylococcus spp. The inhibition of bacterial growth by seven extracts of $A$. aroma is summarized in Table 1 . The results showed that the ethyl acetate and ethanolic extracts presented the highest activities (inhibition diameters of 14-16 $\mathrm{mm}$ ). The petroleum ether, dichloromethane and methanolic extracts presented low activity against the investigated bacteria (inhibition diameters of $9-10 \mathrm{~mm}$ ). On the other hand, the infusion and decoction show little antibacterial activity against all tested microorganisms (inhibition diameters of $7 \mathrm{~mm}$ ).

Table 1. Antibacterial activity of organic and aqueous extracts of Acacia aroma by agar diffusion method.

\begin{tabular}{cccccccccc}
\hline & & \multicolumn{7}{c}{ Inhibition zone diameter (mm) } \\
\cline { 3 - 9 } Microorganisms & $\boldsymbol{n}$ & $\mathbf{A}$ & $\mathbf{B}$ & $\mathbf{C}$ & $\mathbf{D}$ & $\mathbf{E}$ & F & G & Gen \\
\hline Methicillin-sensitive S. aureus $^{*}$ & 18 & $7.3 \pm 0.3$ & $7.2 \pm 0.2$ & $9.5 \pm 0.4$ & $9.5 \pm 0.4$ & $14.9 \pm 0.8$ & $15.0 \pm 0.8$ & $9.1 \pm 0.3$ & $18.0 \pm 1.0$ \\
Methicillin-resistant S. aureus* & 20 & $7.2 \pm 0.3$ & $7.1 \pm 0.3$ & $9.5 \pm 0.4$ & $9.5 \pm 0.5$ & $15.1 \pm 0.7$ & $15.2 \pm 0.8$ & $9.2 \pm 0.2$ & $17.0 \pm 0.2$ \\
$\quad$ S. aureus ATCC 43300 & 1 & $7.2 \pm 0.3$ & $7.0 \pm 0.0$ & $10.0 \pm 0.0$ & $10.0 \pm 0.0$ & $15.0 \pm 0.0$ & $14.7 \pm 0.3$ & $9.0 \pm 0.1$ & $12.0 \pm 0.5$ \\
$\quad$ S. aureus ATCC 25923 & 1 & $6.9 \pm 1.1$ & $7.4 \pm 0.0$ & $9.1 \pm 0.2$ & $9.5 \pm 0.0$ & $14.5 \pm 0.7$ & $15.0 \pm 0.0$ & $9.0 \pm 0.0$ & $14.0 \pm 0.4$ \\
Methicillin-resistant S. epidermidis* & 16 & $7.2 \pm 0.3$ & $7.1 \pm 0.2$ & $9.4 \pm 0.4$ & $9.3 \pm 0.4$ & $15.0 \pm 0.8$ & $15.3 \pm 0.7$ & $9.1 \pm 0.2$ & $17.0 \pm 0.8$ \\
S. epidermidis ATCC 12228 & 1 & $7.2 \pm 0.3$ & $7.0 \pm 0.0$ & $9.2 \pm 0.3$ & $9.7 \pm 0.3$ & $14.0 \pm 0.0$ & $16.0 \pm 0.0$ & $9.0 \pm 0.0$ & $16.0 \pm 0.4$ \\
\hline
\end{tabular}


Alcohol extracts exhibited a higher degree of antibacterial activity, compared to water extracts. This observation confirmed the evidence from a previous study which reported that alcohol is a better solvent for extraction of antimicrobial substances from medicinal plants than water (22).

DMSO, ethanol, petroleum ether, dichloromethane, diethyl acetate, and methanol blanks showed no inhibitory effect.

Whereas the in vitro results proved that aqueous extracts showed little inhibitory growth activity against Staphylococcus; it is of common knowledge the use of A. aroma leaves in form of decoctions in popular medicine to clean wounds or skin infections. Other components could trigger the immune system helping to strengthen the antibacterial effect inherent to the plant that has not been shown in conditions in-vitro. The ethyl acetate and ethanolic extracts were selected because of their higher antibacterial activity to determine the minimal inhibitory concentration (MIC).

The data obtained, through the determination of MIC are shown in Table 2. The results revealed variability in the inhibitory concentrations of both extracts for Staphylococcus. The MIC values of ethyl acetate and ethanolic extracts were in the range of (concentrations) 2.5 to $10 \mathrm{mg} / \mathrm{ml}$, and 2.5 to 5 $\mathrm{mg} / \mathrm{ml}$ respectively. There is little or no scientific information concerning the antibacterial activity of A. aroma in Argentina. A study on A. aroma, performed in Tucumán, Argentina reported MIC values inferior to our results (3). However, it is difficult to compare the data because several variables influence the results, such as the environmental and climate conditions of the plant, and the choice of the extraction method and antibacterial test. Moreover, there is no standard criteria for the evaluation of the plant activity, therefore, the results obtained by different researchers could be different (21).

Table 2. The MIC values of ethyl acetate and ethanolic extracts of A. aroma against strains of Staphylococcus aureus and Staphylococcus epidermidis. Results are the mean of MIC values followed by the standard deviation.

\begin{tabular}{lccc}
\hline Microorganisms & $\boldsymbol{n}$ & $\begin{array}{c}\text { MIC (mg/ml) } \\
\text { ethyl acetate extract }\end{array}$ & $\begin{array}{c}\text { MIC (mg/ml) } \\
\text { ethanolic extract }\end{array}$ \\
\hline Methicillin-sensitive $S$. aureus & 18 & $2.5 \pm 1.1$ & $2.5 \pm 1.0$ \\
Methicillin-resistant $S$. aureus & 20 & $2.5 \pm 1.7$ & $2.5 \pm 1.4$ \\
S. aureus ATCC 43300 & 1 & $10.0 \pm 0.1$ & $2.5 \pm 0.0$ \\
S. aureus ATCC 25923 & 1 & $10.0 \pm 0.0$ & $2.5 \pm 0.1$ \\
Methicillin-resistant S. epidermidis & 16 & $10.0 \pm 0.6$ & $5.0 \pm 0.4$ \\
S. epidermidis (ATCC 12228) & 1 & $10.0 \pm 0.0$ & $5.0 \pm 0.2$ \\
\hline
\end{tabular}

$n$ : strain number; results are the mean of inhibition zone diameter followed by the standard deviation.

Methicillin resistant $S$. aureus and methicillin resistant $S$. epidermidis strains which are already known to be multirresistant to drugs were highly susceptible to ethyl acetate and ethanolic extracts. Likewise, methicillin susceptible $S$. aureus strains were also inhibited by both extracts; that is to say, the Staphylococcus spp. susceptibility to the most active extracts of $A$. aroma did not correlate with the susceptibility or resistance to oxacillin, in agreement with Arias et al.

To obtain some information on the active components, ethyl acetate and ethanolic extracts were analyzed by TLC on silica gel. TLC plates were run in duplicate and one set was used as the reference chromatogram, and the other set was assayed for bioautography. TLC analysis revealed the presence of flavonoids: rutine $\left(\mathrm{R}_{\mathrm{f}}\right.$ of 0.71$)$ and quercetin $\left(\mathrm{R}_{\mathrm{f}}\right.$ of 0.94$)$ and sapogenines: oleanolic acid $\left(\mathrm{R}_{\mathrm{f}}\right.$ of 0.87$)$ and $\beta$ amirine $\left(\mathrm{R}_{\mathrm{f}}\right.$ of 0.50). This is in agreement with observations by other authors (3). The bioautography assay for qualitative antibacterial activity detection demonstrated well-defined inhibition zones 
against $S$. aureus (Fig. 1) in correspondence with those flavonoids and sapogenines bands, although the sapogenines showed less visible zones of inhibition. Antimicrobial activity of flavonoids and saponines has also been reported against methicillin-resistant Staphylococcus aureus (1, 10, 11, 23, 24), however studies regarding the mode of action for these compounds in the bacterial cell should be done.

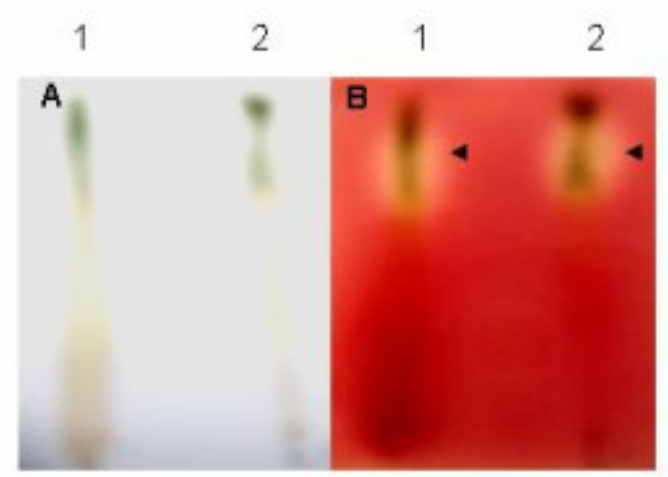

Figure 1. TLC of Acacia Aroma ethyl acetate extract. (A) Visual appearance; (B) Staphylococcus aureus (ATCC 43300) bioautography overlay. Arrows indicate regions of inhibition growth visualised with tetrazolium red. (1) Crude ethyl acetate extract, (2) Rutine (flavonoids standard)

Our results suggest that Acacia aroma extracts possess compounds with antibacterial properties which can be used as bacterial growth inhibitory agents in new drugs for therapy Staphylococcus diseases. Although this study investigated the in vitro antibacterial activity, however, in vivo data may be favorable for determining the potential usefulness of this plant. Further work, including fractioning to isolate active constituents and subsequent pharmacological evaluation, is needed.

Investigations are in progress to determine the degree of toxicity of these extracts. Acacia aroma is a promising plant as its antibacterial activity showed effective results in treatment against the MRSA. Our findings can set the basis for further studies to obtain optimized preparations of the herbal extract with activity against Staphylococcus.

\section{ACKNOWLEDGEMENT}

This work is part of the Project 8802 financed by Universidad Nacional de San Luis, Argentina.

\section{REFERENCES}

1. Alcaraz, L.E.; Blanco, S.E.; Puig, O.N.; Tomas, F.; Ferreti, F.H. (2000). Antibacterial activity of flavonoids against methicillin-resistant Staphylococcus aureus strains. J. Theor. Biol. 205, 231-240.

2. Appel Baum, P.C. (2007). Reduced glycopeptides susceptibility in methicillin-resistant Staphylococcus aureus (MRSA). Int. J. Antimicrob. Agents. 30, 398-408.

3. Arias, M.E.; Gomez, J.D.; Cudmani, N.M.; Vattuone, M.A.; Isla, M.I. (2004). Antibacterial activity of ethanolic and aqueous extracts of Acacia aroma Gill. Ex Hook et Arn. Life Sciences. 75, 191-202.

4. Burkart, A. (1952). Las leguminosas argentinas silvestres y cultivadas. Acme Agency, Buenos Aires, 569 pp.

5. Cabrera, A.L. (1971). Fitogeografía de la República Argentina. Boletín de la Sociedad Argentina de Botánica XIV, (1-2), 15-16.

6. Chomnawang, T.M.; Surassmo, S.; Ukoolkarn V.S.; Gritsanapan, W. (2005). Antimicrobial effects of thaimedicinal plants against acneinducing bacteria. J Ethnopharmacol. 101, 330-333.

7. Cowan, M.M. (1999). Plant products as antimicrobial agents. Clin. Microbiol. Rev. 12, 564-582.

8. Essawi, T.; Srour, M. (2000). Screening of some Palestinian medicinal plants for antibacterial activity. J Ethnopharmacol. 70, 343-349.

9. Farmacopea Nacional Argentina (1978). Codex Medicamentarius Argentine. Sexta Edición. Bs.As. Editorial Codex, S.A.

10. Hernández, N.C.; Tereschuk, M.L.; Abdala, L.R. (2000). Antimicrobial activity of flavonoids in medicinal plants from Tafí del Valle (Tucumán, Argentina). J Ethnopharmacol. 73, 317-322.

11. Kannabiran, K.; Thanigaiarassu, R.; Khanna, V. (2008). Antibacterial activity of saponin isolated from the leaves of Solanum trilobatum Linn. JABS. 2, 109-112.

12. Kuklinski, C. (2000). Farmacognosia. Ed. Omega S.A. España.

13. Levy, S.B. (2002). Factors impacting on the problem of antibiotic resistance. J. Antimicrob. Chemother.. 49, 25-30.

14. Li, M.; Diep, B.M; Villaruz, A.; Braughton, K.; Jiang, X.; Deleo, F.; Chambers, H.; Lu yuan, O. (2009). Evolution of virulence in epidemic community-associated methicillin-resistant Staphylococcus aureus. Proc Natl Acad Sci USA. 106, 5883-5888.

15. Murray, P.; Rosenthal, K.; Pfaller, M. (2006). Microbiología Médica. Quinta Edición. España. Editorial Elsevier S.A.

16. Nascimento Gislene, G.F.; Locatelli, J.; Freitas, P.C.; Silva, G.L. (2000). Antibacterial activity of plant extracts and phytochemicals on antibioticresistant bacteria. Braz. J. Microbiol. 31, 247-256. 
17. Pallecchi, L.;Lucchetti, C.; Bartoloni, A.; Bartalesi, F.; Mantella, A.; Gamboa, H.; Carattoli, A.; Paradisi, F.; Rossolini G. (2007). Population Structure and Resistance Genes in Antibiotic-Resistant Bacteria from a Remote Community with Minimal Antibiotic Exposure. Antimicrob. Agents Chemother. 51, 1179-1184.

18. Palombo, E.; Semple, S.J. (2002). Antibacterial activity of Australian plant extracts against methicillin-resistant Staphylococcus aureus (MRSA) and Vancomycin resistant enterococci (VRE). J. Basic Microbiol. 42, 444-448.

19. Perez, C.; Pauli, M.; Bazevque, P. (1990). An antibiotic assay by the agar well diffusion method. Acta Biologiae et Medicinal Experimentalis. 15, 113-115.

20. Rasmussen, T.B.; Givskov, M. (2006). Quorum sensing inhibitors: a bargain of effects. Microbiology. 152, 895-904.

21. Rios, J.L.; Recio, M.C.; Villar, A. (1988). Screening methods for natural products with antimicrobial activity: a review of the literature. $J$
Ethnopharmacol. 23, 127-149.

22. Rojas, J.J.; Ochoa, V.J.; Ocampo, S.A.; Muñoz, J.F. (2006). Screening for antimicrobial activity of ten medicinal plants used in Colombian folkloric medicine: A possible alternative in the treatment of nonnosocomial infections. BMC Complementary and Alternative Medicine 6, http://www.biomedcentral.com/1472-6882/635.

23. Soetan, K.O.; Oyekunle, M.A.; Aiyelaagbe, O.O.; Fafunso, M.A. (2006). Evaluation of the antimicrobial activity of saponins extract of Sorghum bicolor L. Moench. African J. Biotechnol. . 5, 2405-2407.

24. Tanaka, H.; Sato, M.; Fujiwara, S.; Hirata, M.; Etoh, H.; Takeuchi, H. (2007). Antibacterial activity of the flavonoids isolated for Erythrina variegate against methicillin-resistant Staphylococcus aureus. Lett. Appl. Microbiol. 35, 494-498.

25. Zampini, I.C.; Vattuone, M.A.; Isla, M.I. (2005). Antibacterial activity of Zuccagnia punctata Cav. ethanolic extracts. J Ethnopharmacol. 102, 450-456. 